\title{
Party Poppers and Balloons: Fun and Games or Lives and Limbs?
}

\author{
Fiza Shaheen ${ }^{1}$, Rehan Naqaish ${ }^{2}$, Amer Awan $^{3}$ \\ ${ }^{1-3}$ Department of Ophthalmology, Shifa International Hospital, Shifa College of Medicine (STMU), Islamabad
}

\begin{abstract}
We report two cases of ocular trauma caused by recently popular party poppers and LED balloons, commonly used in parties nowadays. One case depicted a closed globe injury as a result of a party popper spray over the eye. The pressure of the spray resulted in a blunt trauma causing full thickness macular hole which was later treated with Pars Plana Vitrectomy (PPV) surgery. The second case is an example of an open globe injury caused by the bursting of LED balloon over the eye of a young child resulting in corneal perforation, traumatic cataract, vitreous hemorrhage with an intraocular foreign body (IOFB). It was successfully treated with corneal suturing, lens extraction, PPV surgery and removal of IOFB followed by a secondary lens implantation. Both of the sustained injuries were completely avoidable hence emphasizing the requirement of eye safety awareness programs and diligence in the use of these gadgets in everyday lives.
\end{abstract}

Key Words: Ocular trauma, Macular hole, Intra ocular foreign body, Pars Plana Vitrectomy.

How to Cite this Article: Shaheen F, Naqaish R, Awan A. Party Poppers and Balloons: Fun and Games or Lives and Limbs? Pak J Ophthalmol. 2020; 36 (1): 176-178.

Doi: $10.36351 /$ pjo.v36i1.975

\section{INTRODUCTION}

Ocular injury is one the leading causes of visual impairment worldwide causing blindness in approximately 1.6 million people with children being at a greater risk due to their inability to characterize the nature of objects. ${ }^{1}$ Most of these injuries being preventable by the utilization of various simple measures make this a matter of concern. ${ }^{2-5}$

With the advancements in the fields of engineering and technology and incorporation of various gadgets in our daily lives without their implications is a serious concern. One of such example is commonly used party accessories and decorations including Party poppers, foam sprays, helium balloons, LED (light emitting diode) lights and LED balloons.

Correspondence: Fiza Shaheen,

Post Graduate Trainee, Shifa International Hospital, Islamabad. Email: fiza_shaheen@hotmail.com

Received: December 20, 2019

Accepted: February 2, 2020
We report two cases of trauma with party accessories resulting in serious ocular injuries.

\section{CASE 1:}

A 20 years old lady presented in our outpatient department with one-week history of sudden loss of vision in her left eye after direct injury with the spray of a party popper. Her visual acuity was counting fingers close to face with sluggishly reacting left pupil. Her anterior segment was normal but her fundus examination revealed a full thickness macular hole. Optical coherence tomography confirmed it and the width of hole was 1192 microns at base and 492 microns at apex.

She underwent 27 gauge 3 ports Pars Plana Vitrectomy (3PPV), inner limiting membrane (ILM) peel and 18\% C2F6 gas tamponade. Posterior vitreous detachment was induced and complete vitrectomy was performed. ILM was peeled with adjunct use of ILM blue dye. Fluid air exchange was carried out in the end 
which was followed by $18 \%$ C2F6 gas injection. Wounds were secured and sub conjunctival gentamycin and dexamethasone were injected. Post operatively she was started on topical antibiotics and steroid for a period of 4 weeks. One week postoperatively, her visual acuity was hand movement with $65 \%$ gas in the vitreous cavity. Her OCT Scan showed closure of macular hole (Figure 1B). After one month post-operatively her visual acuity had improved to 0.9 logarithm of minimum angle of resolution (logMAR). At two months post operatively it further improved to $0.3 \log -\mathrm{MAR}$.

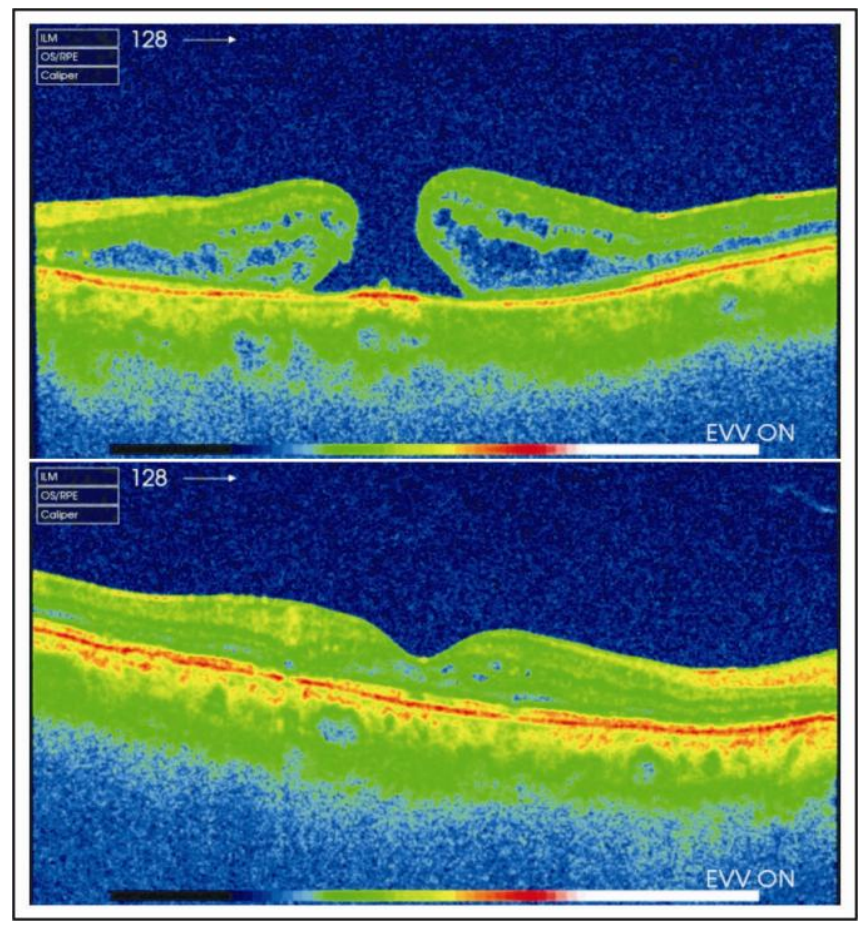

Fig. 1: Above: Post traumatic Full thickness macular hole. Below: Post Vitrectomy closure of macular hole.

\section{CASE 2:}

A 4 years old young girl presented to emergency department with the history of trauma due to the bursting of a LED balloon in front of her right eye few hours prior to presentation and complained of severe pain, watering and redness. Visual acuity could not be assessed as the child was very irritable. On examination there was a central and superior full thickness corneal laceration with iris prolapse along with the suspicion of a superior lenticular opacity. Her cornea was sutured with 10-0 nylon immediately under general anesthesia (GA). Necrotic superior iris strands were excised. Lens was opaque and there was a superior capsular tear as well. It was decided to leave the cataract and remove it later.

She was referred to our vitreoretinal team for further management. Her B Scan ultrasonography was carried out which showed a hyper reflective IOFB in the vitreous cavity with dense vitreous hemorrhage (Figure 2A).

She underwent right cataract extraction and $27 \mathrm{G}$ 3-port PPV under GA. After cataract extraction, two $27 \mathrm{G}$ scleral ports were made and infusion was inserted in anterior chamber. Dense vitreous hemorrhage was cleared and a large metallic foreign body of approximately $7 \mathrm{~mm}$ in length was found lying over the macula (Figure-2C). It was lifted with micro forceps and removed through corneal incision. Peripheral vitrectomy was completed and retinal periphery was searched via scleral indentation. Laser was done nasal to the macula at the suspected site of impact. Corneal wounds were closed with $10-0$ nylon and sclerotomies with $6-0$ Vicryl followed by sub conjunctival gentamycin and dexamethasone injections. Post operatively, the patient was given topical steroids and antibiotics for a month.

Foreign body that was removed was later confirmed to be present inside the LED balloon. It was a hook attached with the encased battery and bulb used inside the balloon (Figure 2B).

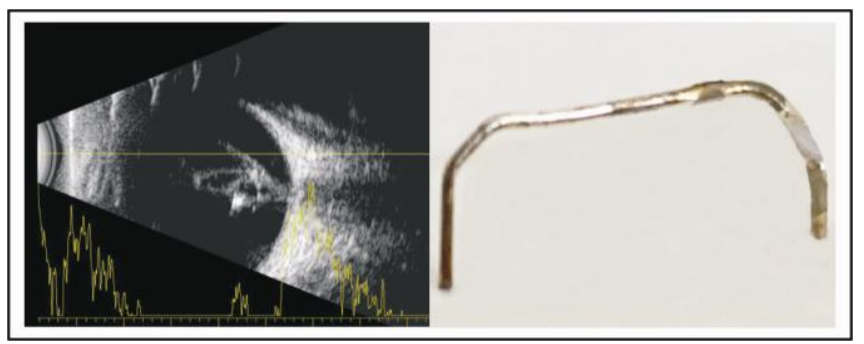

Fig. 2: (Left): B scan showing a hyper reflective IOFB with dense vitreous hemorrhage. (Right): Large metallic foreign body removed from the vitreous cavity.

At 3 months her visual acuity was 0.9 log-MAR with +13.00 Diopter spherical lens. After two and half months, secondary lens implant in the sulcus was performed after which her visual acuity improved to $0.5 \log$-MAR with best correction. Later she was advised patching to prevent amblyopia and vision further improved to $0.3 \log$-MAR. 


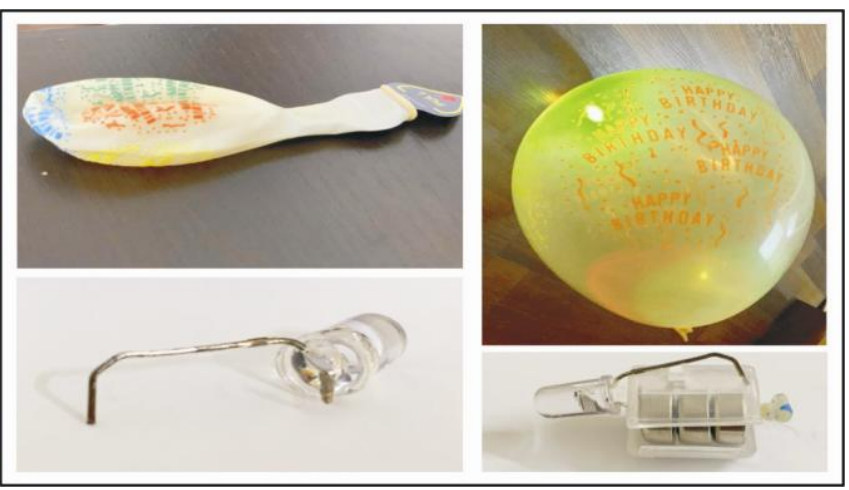

Fig. 3: LED balloon uses an encased battery attached with an LED bulb via hook.

\section{DISCUSSION}

Ocular trauma is quiet common especially in the developing countries accounting for $12.9 \%$ of all the admitted cases. ${ }^{6}$ The common causes include injury with bow and arrows, needles, tools and hooks and firecracker injury. According to the Ocular Trauma Classification group, nature of injuries can be classified as closed globe injuries and open globe injuries as well as a third group of chemical injuries. ${ }^{7}$

Ocular trauma with party accessories was reported in another study in which chemical injuries caused by snow sprays including chemical conjunctivitis, superficial punctate keratopathy, corneal and conjunctival erosions. ${ }^{8}$ Other studies described the ocular injuries caused by water balloon slingshots. Pellet gun injuries have been mentioned in local literature. ${ }^{10}$

The two cases we have described above highlight the potential of these gadgets in causing open as well as closed globe injuries. Although the introduction of various hi tech gadgets in our everyday life style have improved the quality of life in various ways, their use must be accompanied with safety measures. There should be proper guidelines regarding their utility and the description of their potential harm must be discussed. With the common utilization of these devices, such devastating incidents might increase in the future which should be effectively tackled before time.

\section{CONCLUSION}

We strongly stress the need of awareness programs using social and media services. Party accessories although intended for fun, must be carefully used if not possibly avoided.

\section{Conflict of Interest}

Authors declared no conflict of interest.

\section{REFERENCES}

1. Qayum S, Anjum R, Rather S. Epidemiological profile of pediatric ocular trauma in a tertiary hospital of northern India. Chinese J Ophthalmol. 2018; 21 (2): 100-103.

2. Niiranen M, Raivio IL. Eye injuries in children. Br J Ophthalmol. 1981; 65 (6): 436-438.

3. Grin TR, Nelson LB, Jeffers JB. Eye injuries in childhood. Pediatrics. 1987; 80 (1): 13-17.

4. LaRoche GR, McIntyre L, Schertzer RM. Epidemiology of severe eye injuries in childhood. Ophthalmology, 1988; 95 (12): 1603-1607.

5. Nelson LB, Wilson TW, Jeffers JB. Eye injuries in childhood: demography, etiology, and prevention. Pediatrics, 1989; 84 (3): 438-441.

6. Thylefors B. Epidemiological patterns of ocular trauma. Aus New Zeal J Ophthalmol. 1992; 20 (2): 9598.

7. Saxena R, Sinha R, Purohit A, Dada T, Vajpayee RB, Azad RV. Pattern of pediatric ocular trauma in India. Indian J Pediatr. 2002 Oct. 1; 69 (10): 863-867.

8. Abulafia A, Segev F, Platner E, Simon GJ. Party foam-induced eye injuries and the power of media intervention. Cornea, 2013; 32 (6): 826-829.

9. Bullock JD, Johnson DA, Ballal DR, Bullock RJ. Ocular and orbital trauma from water balloon slingshots: a clinical, epidemiological, experimental and theoretical study. Trans Am Ophthalmol Soc. 1996; 94:105-134.

10. Bahoo MLA, Jamil AZ, Karamat B. Frequency and characteristics of ocular trauma in a Tertiary Care Hospital in Lodhran. Pak J Ophthalmol. 2019; 35 (2): 116-120.

\section{Authors' Contribution}

Fiza Shaheen: Manuscript drafting, literature review and final review.

Rehan Naqaish: literature search and final review.

Amer Awan: literature search and final review. 